\title{
Aminotrimethylene Phosphonic Acid and Sodium Ethyl Xanthate for Purification of Stripped Phosphoric Acid Produced from Commercial Acid by Solvent Extraction
}

\author{
M. I. Amin ${ }^{\#}$ and E. A. Nouh \\ Nuclear Materials Authority, Cairo, Egypt.
}

\begin{abstract}
D HOSPHORIC acid is the second most produced acid after $\mathrm{H}_{2} \mathrm{SO}_{4}$. It was used as a raw material for the production of detergents, food products, and alimentary supplies for cattle, toothpastes and fertilizers. High grade phosphoric acid was obtained using liquid-liquid extraction with aliphatic alcohols to separate metal and fluoride ion impurities in the aqueous phase. The influence of alcohol concentration, organic/aqueous phase ratio, temperature, shaking time and phosphoric acid concentration on $\mathrm{P}_{2} \mathrm{O}_{5}$ extraction was studied. N-Nonanol proved to be the most efficient and selective alcohol and the temperature had a slight positive effect and the extraction was enhanced by increasing $\mathrm{P}_{2} \mathrm{O}_{5}$ and with the increase of organic/aqueous phase ratio. The optimum organic/aqueous phase ratio was determined to be 2.0. Stripping was also investigated, the purification of stripped phosphoric acid was achieved using sodium ethyl xanthate where $95.1 \%$ of iron was removed, also aminotrimethylene phosphonic acid can be successfully used for decreasing iron content to $190.9 \mathrm{ppm}$ and to produce highly pure grade phosphoric acid.
\end{abstract}

Keywords: Aminotrimethylene phosphonic acid, Sodium ethyl xanthate, Stripped phosphoric acid solution and Solvent extraction technique.

Wet process phosphoric acid (WPA) contains many impurities beside solids and organic matters ${ }^{(1)}$. In particular, the reduction of fluoride content during the manufacture of WPA to a very low concentration has been studied ${ }^{(2)}$ and there has been a wide interest over the last few years to develop a process for the purification of commercial WPA using solvent extraction. Many solvents were tried but aliphatic alcohols have the advantages of being efficient, cheap, easy to use, separate quickly and do not pollute the food grade acid produced. The purification of WPA by di-isopropyl ether (DIPE) was studied ${ }^{(3)}$. The partition coefficient, $K$ of WPPA between water and DIPE at different temperatures was determined. The average value amounted to $4.7 \times 10^{-2}$ at $25^{\circ} \mathrm{C}$, decreasing as the temperature increased from 25 to $55^{\circ} \mathrm{C}$. The extraction of WPA is apparently more favorable around room temperature. It was also found that the extraction of phosphoric acid in the organic layer increased, the greater solvent/acid weight

\#E-mail address: Mostafa_nm@yahoo.com

Tel.: (002) 01229664979 
ratio was. The batch wise extraction and stripping of phosphoric acid from $200 \mathrm{ml}$ crude acid yielded $39.0 \mathrm{~g}$. of pure phosphoric acid, $154.7 \mathrm{~g}$. of pure $\mathrm{Na}_{2} \mathrm{HPO}_{4} \cdot 7 \mathrm{H}_{2} \mathrm{O}$ and 215.2 g. of pure $\mathrm{Na}_{3} \mathrm{PO}_{4} \cdot 8 \mathrm{H}_{2} \mathrm{O}$ beside 75.0 g. of a precipitated cake during the chemical treatment of the raffinate.

The extraction of uranium and heavy metals was negligible, while the extraction of fluorine and iron was relatively small. The solvent extraction of phosphoric acid from various aqueous solutions has also been investigated using tributyl-phosphate (TBP) ${ }^{(4)}$ and methyl isobutyl ketone (MIBK). Purification of WPA with mixtures of MIBK and TBP gave the greatest recovery of $\mathrm{P}_{2} \mathrm{O}_{5}$ with $55 \%$ MIBK- $45 \%$ TBP and a phase diagram of the ternary system $\mathrm{H}_{3} \mathrm{PO}_{4}$-wateroptimal solvent mixture was determined ${ }^{(5)}$. The purification of commercial $\mathrm{H}_{3} \mathrm{PO}_{4}$ from metallic impurities was studied using $2.55 \mathrm{M}$ TBP in kerosene ${ }^{(6)}$ and about $90 \% \mathrm{P}_{2} \mathrm{O}_{5}$ in $9.2 \mathrm{M} \mathrm{H}_{3} \mathrm{PO}_{4}$ was extracted in three stages at room temperature. However, the purification of WPA with MIBK was systematically studied with regard to the distribution of the major impurities $\left(\mathrm{Ca}^{2+}, \mathrm{Mg}^{2+}, \mathrm{Al}^{3+}, \mathrm{Fe}^{3+}, \mathrm{SO}_{4}{ }^{2-}, \mathrm{F}\right)$ between the conjugated phases at $40^{\circ} \mathrm{C}$. The purity of $\mathrm{H}_{3} \mathrm{PO}_{4}$ was computed by counter current multistage extraction using the McCabe-Thiele method. The aim of the present work is to compare and contrast heptanol, and nonanol in kerosene as extractants for $\mathrm{H}_{3} \mathrm{PO}_{4}$ to determine the role of the different parameters contributing to the extraction process. A major aim was the specification of phosphoric acid, before and after solvent extraction to achieve a high grade product, and the determination of the McCabe-Thiele extraction diagram.

\section{Experimental}

\section{Materials and measurements}

Normal heptanol and nonanol (BDH) with 99\% purity were used, aminotrimethylene phosphonic acid with 99\% (AR), sodium ethyl xanthate from the Dow Chemical Company, California and Commercial WPA having the following components $\left(\mathrm{P}_{2} \mathrm{O}_{5}=44.0 \%, \mathrm{Fe}=2.6 \%, \mathrm{Cu}=0.0012 \%, \mathrm{Cd}=0.001 \%\right.$, $\mathrm{F}=0.7 \%$ ) was supplied from Abu-Zaabal Co., Cairo, Egypt. Abu Tartur bentonite was used. All chemicals and reagents were of A.R. grade and used without further purification. $\mathrm{Fe}, \mathrm{Cd}$ and $\mathrm{Cu}$ were determined by GBC 932- AAS. The fluoride content was determined by ion selective electrode, a Genway, model $3330 \mathrm{pH}$ meter equipped with Orion model 94-09 BN fluoride electrode. $\mathrm{P}_{2} \mathrm{O}_{5}$ was determined spectrophotometrically. The concentration of $\mathrm{P}_{2} \mathrm{O}_{5}$ in the solvent was calculated from the material balance. The yield was calculated from the equation:

$$
\text { Yield }(\mathrm{Y} \%)=\frac{\left[\mathrm{P}_{2} \mathrm{O}_{5}\right]_{\text {feed acid }}-\left[\mathrm{P}_{2} \mathrm{O}_{5}\right]_{\text {raffinate }}}{\left[\mathrm{P}_{2} \mathrm{O}_{5}\right]_{\text {feed acid }}} \times 100 \ldots \ldots(1)
$$


The distribution ratio $(D)$ was calculated from the equation:

Total concentration of $\mathrm{P}_{2} \mathrm{O}_{5}$ in organic phase

$\mathrm{D}=$

Total concentration of $\mathrm{P}_{2} \mathrm{O}_{5}$ in aqueous phase

\section{Analytical procedures}

Acid pre-treatment

Crude phosphoric acid (9.2M) was mixed with bentonite $(11.67 \mathrm{~g} / \mathrm{l})$ for $30 \mathrm{~min}$. and the acid was left to settle down. Polycrylamide type $(0.5 \mathrm{mg} / \mathrm{l})$ as a flocculating agent was added to enhance the settlement of the suspended materials.

Production of partially purified phosphoric acid

Pre-treated phosphoric acid was partially purified $^{(7)}$ before applying solvent extraction technique to decrease the concentration of fluoride by precipitation using $5.9 \mathrm{~g} / / \mathrm{L} \mathrm{SiO}_{2}+10.5 \mathrm{~g} / \mathrm{L} \mathrm{Na}_{2} \mathrm{CO}_{3}$.

Extraction process of $\mathrm{P}_{2} \mathrm{O}_{5}$

The extraction process of $\mathrm{P}_{2} \mathrm{O}_{5}$ was carried out from different concentrations of WPA. The different parameters investigated were: solvent concentration, temperature, shaking time and org. / aq. phase ratio. Different volumes of organic and aqueous phases were equilibrated for 10 min under vigorous shaking in a thermostated water bath. After phase separation, the concentration of $\mathrm{P}_{2} \mathrm{O}_{5}$ in the aqueous phase before and after extraction was determined. Also, the extraction percent $\left(\mathrm{E}_{\text {extn }}{ }^{\prime} \%\right)$ was calculated

$$
\left(\mathrm{E}_{\text {Extn. }}, \%\right)=\frac{\mathrm{D}+\mathrm{V}_{\mathrm{aq}} / \mathrm{V}_{\mathrm{org}}}{\mathrm{D}}
$$

Shaking time is an important factor in determining the efficiency of liquidliquid extraction processes which involve mass transfer between two liquids. The effect of shaking time was investigated between 1.0 and 30.0 min under the following conditions: $\left(\mathrm{H}_{3} \mathrm{PO}_{4}=9.20 \mathrm{M}, \mathrm{O} / \mathrm{A}=1: 4\right.$ and 1:6 for heptanol and nonanol, respectively, $\mathrm{T} 25^{\circ} \mathrm{C}$ ). From the results, there was little difference after shaking for $5 \mathrm{~min}$. Evidently the extraction was found to be rapid indicating that diffusion which is influenced by stirring has very little influence on extraction.

\section{Stripping investigation}

The stripping investigations were carried out to determine the best condition that can successfully strip $\mathrm{H}_{3} \mathrm{PO}_{4}$ from the organic phase. The effect of shaking time and organic to aqueous ratio were studied. The aqueous and organic phases were shaked for $5 \mathrm{~min}$ and then allowed to settle for $20 \mathrm{~min}$ to separate in a funnel. The stripping efficiency percent was calculated from the equation:

$100 \mathrm{D}$

$$
\left(\mathrm{E}_{\text {Str. }}{ }^{\prime} \%\right)=\frac{100 \mathrm{D}}{\mathrm{D}+\mathrm{V}_{\mathrm{org}} / \mathrm{V}_{\mathrm{aq}}}
$$


The distribution ratio (D) was calculated

$\mathrm{D}=\frac{\text { Total concentration of } \mathrm{P}_{2} \mathrm{O}_{5} \text { in aqueous phase }}{\text { Total concentration of } \mathrm{P}_{2} \mathrm{O}_{5} \text { in organic phase }}$

Removal of iron from stripped phosphoric acid solution using aminotrimethylene phosphonic acid

Removal experiments were carried out in a mechanically agitated and thermostatic beakers containing iron (4650 ppm), in $50 \mathrm{ml}$ of stripped phosphoric acid and different amount of the aminotrimethylene phosphonic acid. The mixture was agitated by a mechanical device at constant stirring speed $400 \mathrm{rpm}$. After 3.0 min, the organic and aqueous phase was separated and the iron concentration was determined in aqueous phase by atomic absorption spectrometer. Whereas the concentration of the iron in the organic phase was calculated from the difference in the iron concentration in the aqueous phase before and after the extraction process, the results were expressed as percent iron extracted.

Removal of iron from stripped phosphoric acid solution using sodium ethyl xanthate

To study the effect of sodium ethyl xanthate on the removal of iron from stripped phosphoric acid solution for production of highly pure grade phosphoric acid, in this concern, different amounts of sodium ethyl xanthat $(0.05-6.00 \mathrm{~g})$ were added to the stripped phosphoric acid and agitated by a mechanical device at constant stirring speed $400 \mathrm{rpm}$.

\section{Results and Discussion}

Liquid-liquid extraction of $\mathrm{P}_{2} \mathrm{O}_{5}$ from wet process phosphoric acid

Effect of phosphoric acid concentration

The effect of phosphoric acid concentration on $\mathrm{E}_{\mathrm{extn}}{ }^{\prime} \%$ was investigated (Fig.1). The extraction of $\mathrm{P}_{2} \mathrm{O}_{5}$ from partially purified phosphoric acid within the concentration range 3.60-9.20 $\mathrm{M}$ was determined. The results reveal that $\mathrm{E}_{\text {extn }}{ }^{\prime} \%$ continuously increases with the increase of the acid concentration to reach 63.00 and $68.00 \%$ for heptanol and nonanol, respectively. The high values of $\mathrm{E}_{\text {extn }}{ }^{\prime} \%$ from $9.2 \mathrm{M} \mathrm{H}_{3} \mathrm{PO}_{4}$ refer to the validity of the present method. In the extracted species, the protons of the acid may form a hydrogen bond with an oxygen atom of the solvent and thus its extraction is quite reasonable. The oxygen atom of the alcohol molecule may combine with the hydrogen atoms of the hydrate water molecule which combines with the proton of the strong acid through its oxygen. So that the Solvation of $\mathrm{H}_{3} \mathrm{PO}_{4}$ by alcohol is by hydrogen bonding between the acid molecule and the alcohol oxygen which may be enhanced by dissolved water in the

Egypt. J. Chem. 56, No. 3 (2013) 
organic phase. Moussa has studied the effect of phosphoric acid concentration on the extraction efficiency of $\mathrm{P}_{2} \mathrm{O}_{5}$ using TBP as organic solvent ${ }^{(4)}$. The obtained date ${ }^{(4)}$ confirmed all the data in the present work.

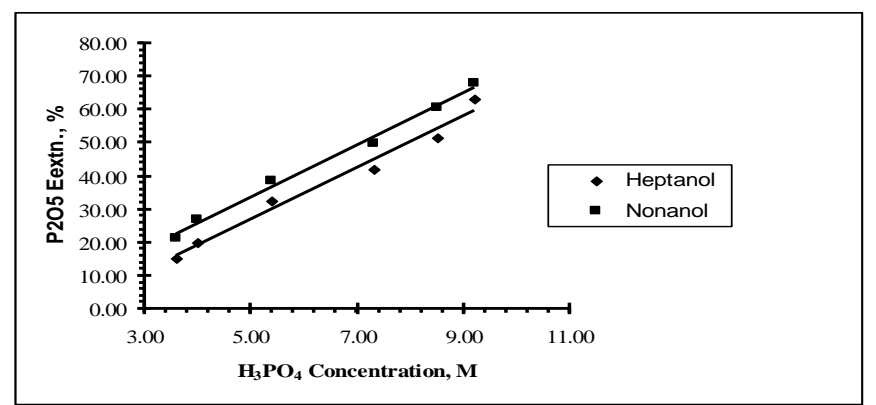

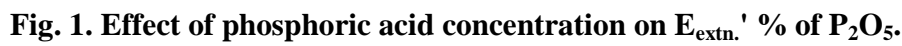

Effect of solvent concentration

The effect of solvent concentration on the $\mathrm{P}_{2} \mathrm{O}_{5}$ extraction from partially purified phosphoric acid $(9.20 \mathrm{M})$ was achieved within the concentration range (1.00-5.56 M) at room temperature. The results (Fig. 2) show that the $\mathrm{E}_{\text {extn }} \%$ of the $\mathrm{P}_{2} \mathrm{O}_{5}$ increases with the increase of alcohol concentration.

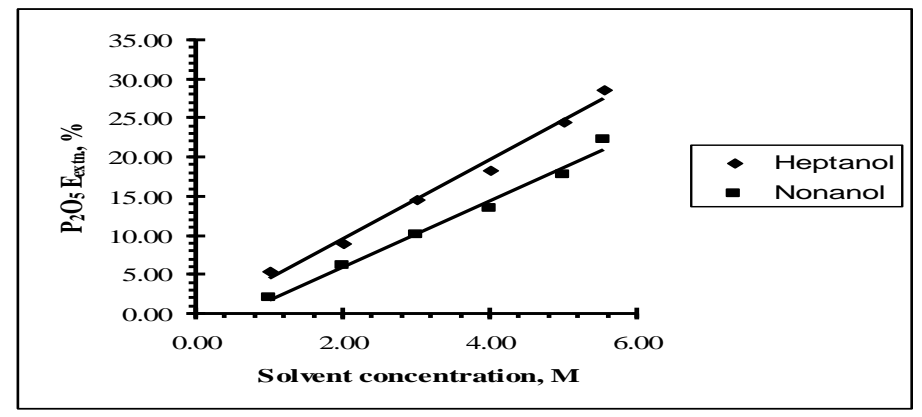

Fig. 2. Effect of alcohol concentration in kerosene on $\mathrm{E}_{\text {extn.' }} \%$ of $\mathrm{P}_{2} \mathrm{O}_{5}$.

Effect of organic to aqueous phase ratio

The effect of changing org. / aq. phase ratio between 1.0 and 6.0 on $\mathrm{E}_{\text {extn }}{ }^{\prime} \%$ of $\mathrm{P}_{2} \mathrm{O}_{5}$ from concentrated phosphoric acid $(9.20 \mathrm{M})$, was investigated using different types of alcohols. From Fig. 3, the obtained results indicate that $\mathrm{E}_{\text {extn }}{ }^{\prime} \%$ of $\mathrm{P}_{2} \mathrm{O}_{5}$ increases by increasing the organic to aqueous phase ratio.

\section{Effect of temperature}

The extraction of $\mathrm{P}_{2} \mathrm{O}_{5}$ from the partially purified phosphoric acid $(9.20 \mathrm{M})$ was investigated at different temperature between 278 and $333 \mathrm{~K}$. The Org./Aq. phase ratios were 1:4 and 1:6 for heptanol and nonanol, respectively and the shaking time was $10.00 \mathrm{~min}$ for all cases. The obtained results are graphically 
represented in Fig. 4 which indicates that $\mathrm{E}_{\text {extn }}{ }^{\prime} \%$ of $\mathrm{P}_{2} \mathrm{O}_{5}$ increased from 58.2 to $67.32 \%$ for heptanol and 64.3 to $71.0 \%$ for nonanol. Economically, the $\mathrm{P}_{2} \mathrm{O}_{5}$ extraction process is preferred at room temperature.

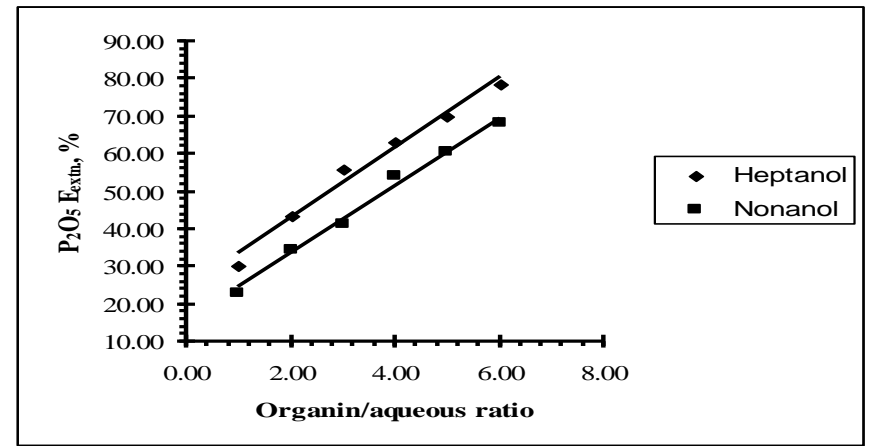

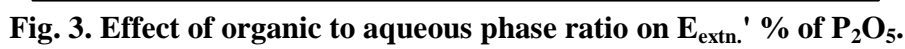

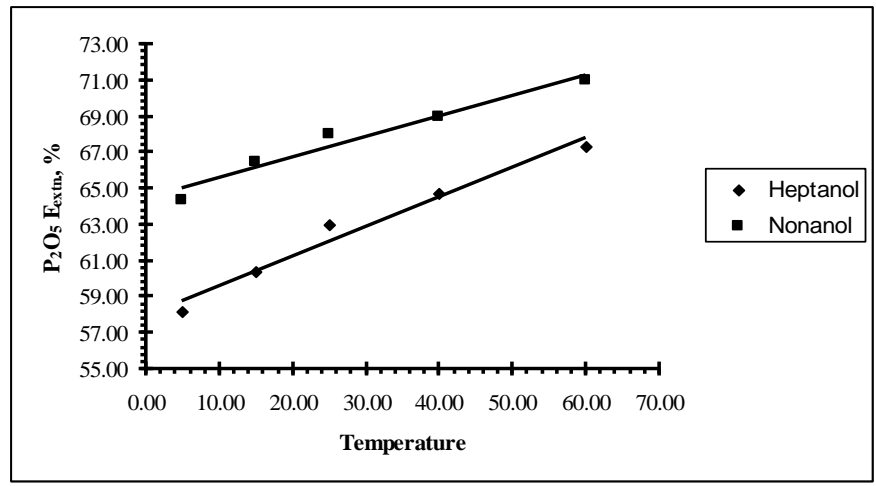

Fig. 4. Effect of temperature on $\mathrm{E}_{\text {extn. }} \%$ of $\mathrm{P}_{2} \mathrm{O}_{5}$.

The results are also plotted in Fig. 5 in the form of $\ln \mathrm{D}$ versus $1000 / \mathrm{T}{ }^{\circ} \mathrm{K}$. The results fit a straight line equation with a slope value -0.498 and -0.674 for heptanol and nonanol, respectively. The relation between the equilibrium constant $K$ and the temperature is given by Vant Hoff equation (Khorfan et al., 2001):

By integration,

$$
\mathrm{d} \ln K / \mathrm{dT}=\Delta \mathrm{H} / \mathrm{R}^{\mathrm{T}} \mathrm{T}^{2}
$$

$$
\ln K=(-\Delta \mathrm{H} / \mathrm{R})(1 / \mathrm{T})+\mathrm{c}, \text { where } \mathrm{c} \text { is constant. }
$$

And since the distribution ratio $D$ is related by definition to the equilibrium constant $K$, the previous equation could be written:

$$
\ln D=(-\Delta \mathrm{H} / \mathrm{R})(1 / \mathrm{T})+\mathrm{c}
$$

It was possible to calculate the enthalpy change $(\Delta \mathrm{H})$. These values are 4.14 and $5.60 \mathrm{KJ} / \mathrm{mol}$ for heptanol and nonanol, respectively. The positive values of 
$\Delta \mathrm{H}$ refer to the positive effect of extraction temperature. The enthalpy change seems to be depending on the chain length of the alcohol extractant.

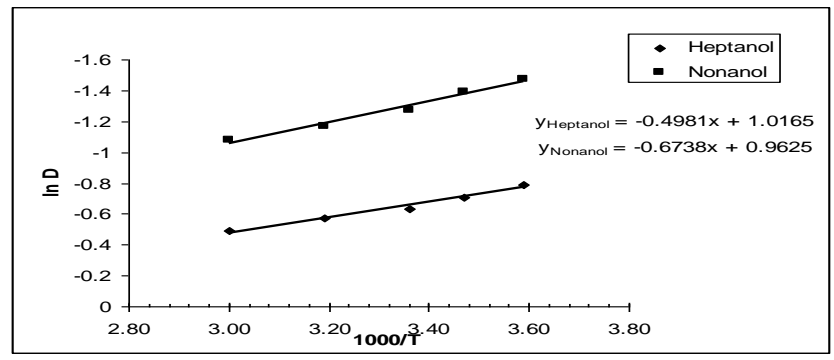

Fig. 5. In $D$ as a function of $1000 / T$.

McCabe-Thiele Diagram for extraction of phosphoric acid using heptanol and nonanol

Considering the optimum conditions for $\mathrm{P}_{2} \mathrm{O}_{5}$ extraction from $9.20 \mathrm{M}$ partially purified phosphoric acid using 6.93 and $5.56 \mathrm{M}$ for heptanol and nonanol, respectively, shaking time of $10.00 \mathrm{~min}$ and at room temperature, wet phosphoric acid extraction equilibrium curve (Fig. $6 \& 7$ ) were used to calculate the number of counter current stages required to achieve about 88.9 and $87.6 \%$ extraction yield at $25{ }^{\circ} \mathrm{C}$ heptanol and nonanol, respectively.

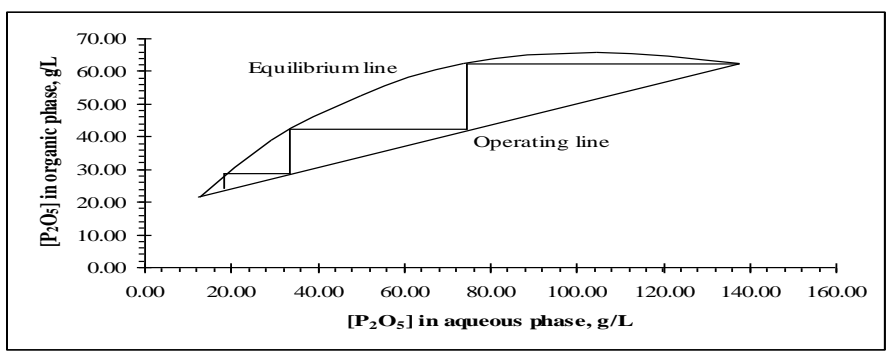

Fig. 6. McCabe-Thiele Diagram for the extraction of $\mathrm{P}_{2} \mathrm{O}_{5}$ using heptanol.

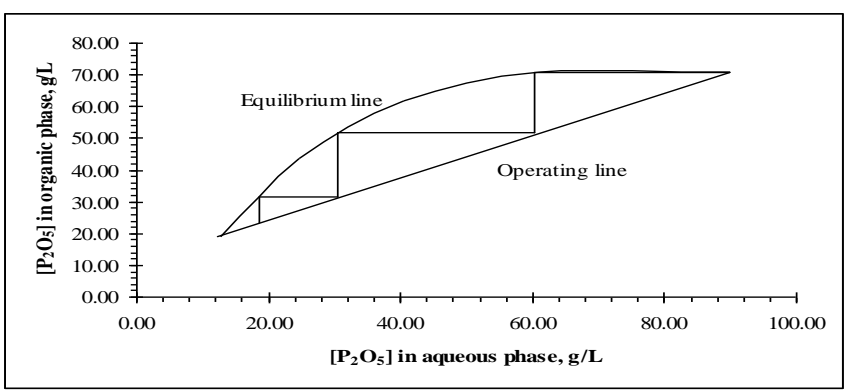

Fig. 7. McCabe-Thiele Diagram for the extraction of $\mathrm{P}_{2} \mathrm{O}_{5}$ using nonanol. 


\section{Stripping process}

Direct re-extraction without scrubbing process of $\mathrm{P}_{2} \mathrm{O}_{5}$ from the loaded organic solvent was investigated using distilled water to obtain diluted phosphoric acid.

\section{Effect of shaking time}

The effect of shaking time on $\mathrm{P}_{2} \mathrm{O}_{5}$ stripping from heptanol and nonanol have been investigated using distilled water with aq./org. phase ratio equal 1.00 at room temperature while the shaking time ranged from 1.00 to $20.00 \mathrm{~min}$. The results are shown in Fig. 8 as a relation between shaking time and $\mathrm{P}_{2} \mathrm{O}_{5}$ stripping percent. The results indicate that stripping efficiency very slightly increases from a value of 82.4 at $1.00 \mathrm{~min}$ to 82.9 at $5.00 \mathrm{~min}$ and 92.05 at $1.00 \mathrm{~min}$ to 92.6 at 5 min for heptanol and nonanol, respectively then remains more or less constant. This indicates that the process is rapid, i.e. is not a diffusion controlled process.

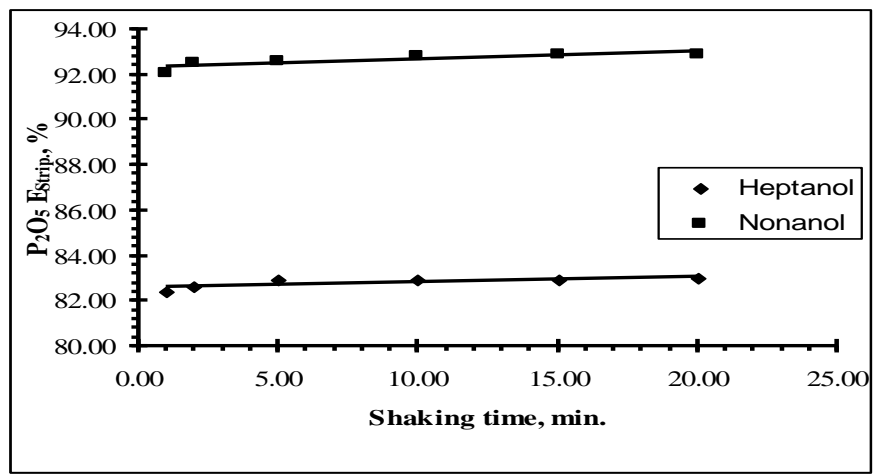

Fig. 8. Effect of shaking time on $\mathrm{E}_{\text {Stripping' }} \%$ of $\mathrm{P}_{2} \mathrm{O}_{5}$.

Effect of aqueous to organic ratio

The effect of aq / org phase ratio on the $\mathrm{P}_{2} \mathrm{O}_{5}$ stripping from heptanol and nonanol has been studied using distilled water at room temperature, while shaking time for $5.00 \mathrm{~min}$. The aq / org phase ratio was varied from 0.25 to 4.00. Figure 9 depicts that upon increasing aq / org ratio, the $\mathrm{P}_{2} \mathrm{O}_{5}$ stripping efficiency increased to exhibit a maximum at a ratio $=2.0$. Further increase of aq / org ratio was associated with a very slight increase of $\mathrm{P}_{2} \mathrm{O}_{5}$ stripping.

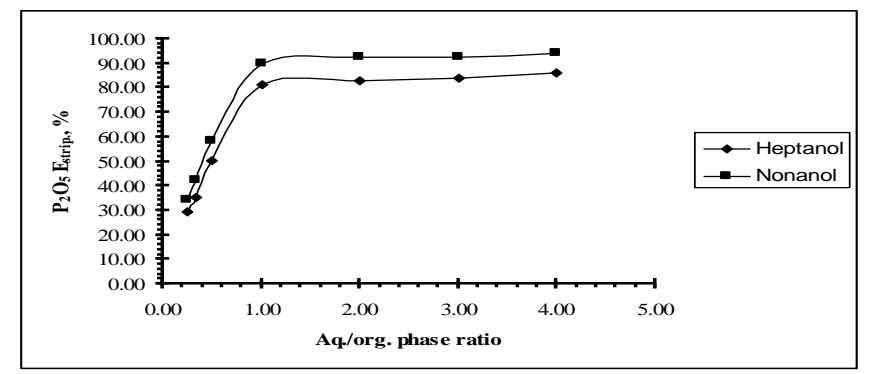

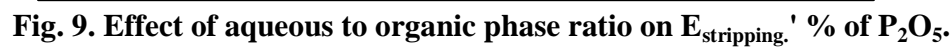

Egypt. J. Chem. 56, No. 3 (2013) 


\section{Purification of stripped phosphoric acid solution}

Stripped phosphoric acid obtained from commercial wet process phosphoric acid by solvent extraction technique using heptanol or nonanol was partially purified acid, The presence of some undesirable impurities such as iron in the stripped solution (4650 and $3200 \mathrm{ppm}$ for heptanol and nonanol, respectively) prevents it to be used in different industrial applications, many successfully trials were achieved to purify phosphoric acid by organic solvent extraction process including scrubbing process, but these trials were very expensive because of applying scrubbing process using pure phosphoric acid, for this reason the purification of stripped phosphoric acid using different and cheap method instead of applying scrubbing process is necessary for production of highly pure grade phosphoric acid.

Purification of stripped phosphoric acid using aminotrimethylene phosphonic acid and sodium ethyl xanthate

The removal of iron from stripped phosphoric acid can be achieved using aminotrimethylene phosphonic acid as follows ${ }^{(8)}$ :

$$
\mathrm{C}_{3} \mathrm{H}_{12} \mathrm{O}_{9} \mathrm{NP}_{3}+\mathrm{Fe}^{+3} \longrightarrow \mathrm{C}_{3} \mathrm{H}_{9} \mathrm{O}_{9} \mathrm{NP}_{3} \mathrm{Fe}+3 \mathrm{H}^{+}
$$

This form involves chelation of one ferric ion with one mole of the ligand, (1:1). Two chelated ferric ions may form when the metal : legand ratio is $(2: 1)$, as follows:

$$
\mathrm{C}_{3} \mathrm{H}_{12} \mathrm{O}_{9} \mathrm{NP}_{3}+2 \mathrm{Fe}^{+3} \longrightarrow \mathrm{C}_{3} \mathrm{H}_{9} \mathrm{O}_{9} \mathrm{NP}_{3} \mathrm{Fe}_{2}+6 \mathrm{H}^{+}
$$

The ferric phosphate chelate can stay soluble in the phosphoric acid or precipitate out depending on many factors including phosphoric acid concentration, concentration of the reagent and temperature. On the other hand, iron can be decreased using another reagent called sodium ethyl xanthate, It seems that xanthate (Xan) acts as an ion exchanger ${ }^{(9)}$.

$$
2 \mathrm{NaXan}+\mathrm{M}^{2+} \longrightarrow \mathrm{MXan}+2 \mathrm{Na}^{+}
$$

(NaXan is sodium xanthate and $\mathrm{M}^{2+}$ is $\mathrm{Fe}$ ), it was further found that some xanthates are more unstable than others in the acid solutions, and one could also get side reactions with for instance, the formation of $\mathrm{CS}_{2}$. The stability of xanthate was found to increase with the amount and degree of branching of the organic part. Regarding the choice of xanthate, it was further found that alkali salts like sodium and potassium were most suitable, while other water soluble metal salts of xanthate could be applied.

Xanthates are salts of dithiocarbonic acid-O-esters having the general formula :

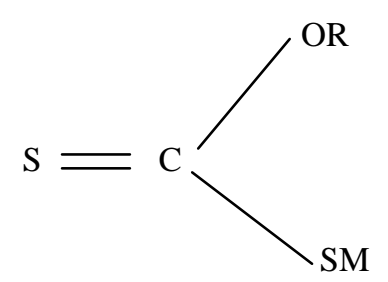

Egypt. J. Chem. 56, No. 3 (2013) 
$\mathrm{R}$ is aryl or alkyl. $\mathrm{M}$ is $\mathrm{Na}$ or $\mathrm{K}$ in commercial xanthate, $(\mathrm{R})$ can have $1-8 \mathrm{C}$ atoms.

Effect of the reagent concentration: The removal of iron from stripped phosphoric acid $\left(20.5 \% \mathrm{H}_{3} \mathrm{PO}_{4}\right)$ was studied at room temperature for using sodium ethyl xanthate while at $60^{\circ} \mathrm{C}$ for aminotrimethylene phosphonic acid. Different amounts of the reagents (0.01-6.00 g) were agitated with $50 \mathrm{ml}$ of the stripped acid. The results (Fig. 10) show that iron removal efficiency increased by increasing the concentration of both added reagents. By the addition of $4.0 \mathrm{~g}$ sodium ethyl xanthate, iron decreased to its minimum value $(980.4 \mathrm{ppm})$ by removal efficiency of $78.5 \%$, while in the case of using aminotrimethylene phosphonic acid, the iron content of the stripped acid was decreased due to the precipitation of ferric phosphonate as sludge. The iron removal efficiency increased to reach its maximum value $98.6 \%$ by the addition of $1.0 \mathrm{~g}$ and then kept constant by the addition of more amounts.

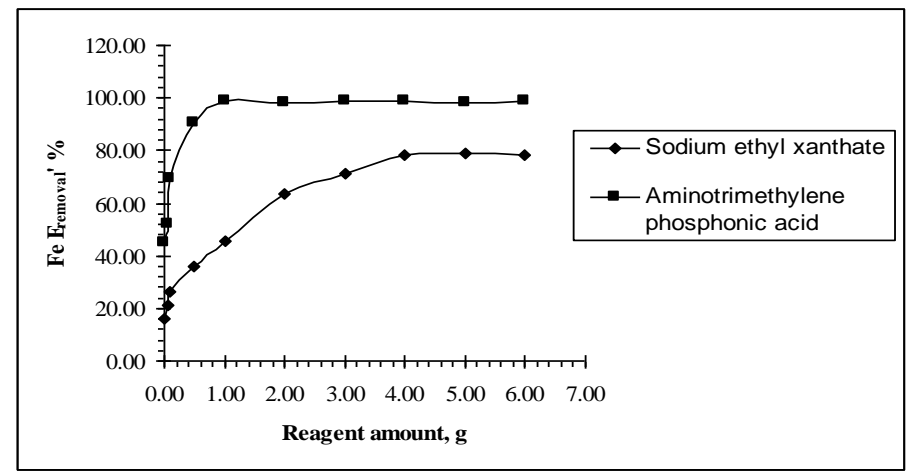

Fig. 10. Effect of the reagent amount on the iron removal efficiency.

Effect of stirring time: Stirring time is an important factor in determining the efficiency of iron removal processes from stripped phosphoric acid. The effect of stirring time was investigated between 0.5 and $6.0 \mathrm{~min}$ under the following conditions: $\left(\mathrm{H}_{3} \mathrm{PO}_{4}=20.5 \%\right.$, sodium ethyl xanthate and $=4.0 \mathrm{~g}$, aminotrimethylene phosphonic acid $=1.0 \mathrm{~g}$ and temperature $=25^{\circ} \mathrm{C}$ for sodium ethyl xanthate while $60^{\circ} \mathrm{C}$ for aminotrimethylene phosphonic acid). The results are graphically presented in Fig. 11 evidently the removal process was found to be very rapid in the case of using aminotrimethylene phosphonic acid, in this case the iron removal process was achieved by stirring for 0.5 min while in the case of removal of iron using sodium ethyl xanthate, the iron removal efficiency increased by increasing the stirring time reached its maximum value by stirring for $5.0 \mathrm{~min}$. 


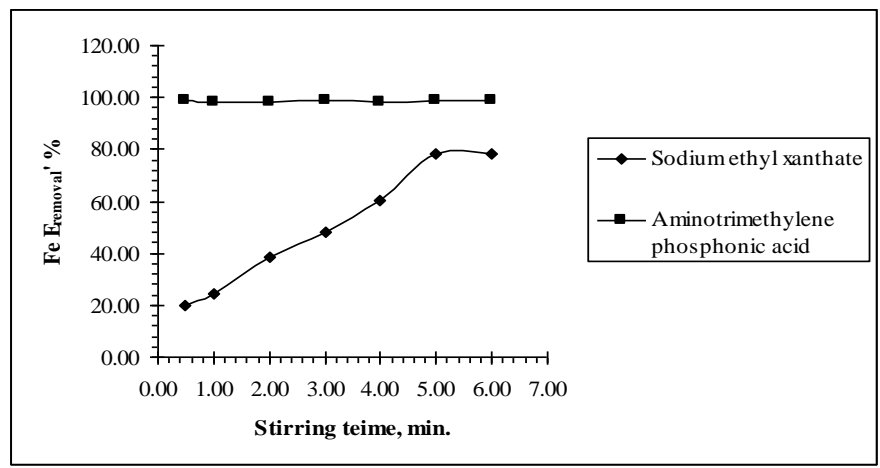

Fig. 11. Effect of stirring time on iron removal efficiency.

Effect of temperature: The removal of Fe from the stripped phosphoric acid $\left(20.5 \% \mathrm{H}_{3} \mathrm{PO}_{4}\right)$ was investigated at different temperature between 25 and $60^{\circ} \mathrm{C}$. (Fig. 12), the stirring time was $5 \mathrm{~min}$ in the case of using sodium ethyl xanthate and $0.5 \mathrm{~min}$ in the case of addition of aminotrimethylene phosphonic acid. By the removal of iron using sodium ethyl xanthate, $\mathrm{E}_{\text {removal }} \%$ of Fe increased from 78.5 to $93.8 \%$ by increasing the temperature from 25 to $60^{\circ} \mathrm{C}$, while in the case of using aminotrimethylene phosphonic acid, the iron removal efficiency decreasing the temperature. This means that the solubility of the chelate increases by decreasing the temperature.

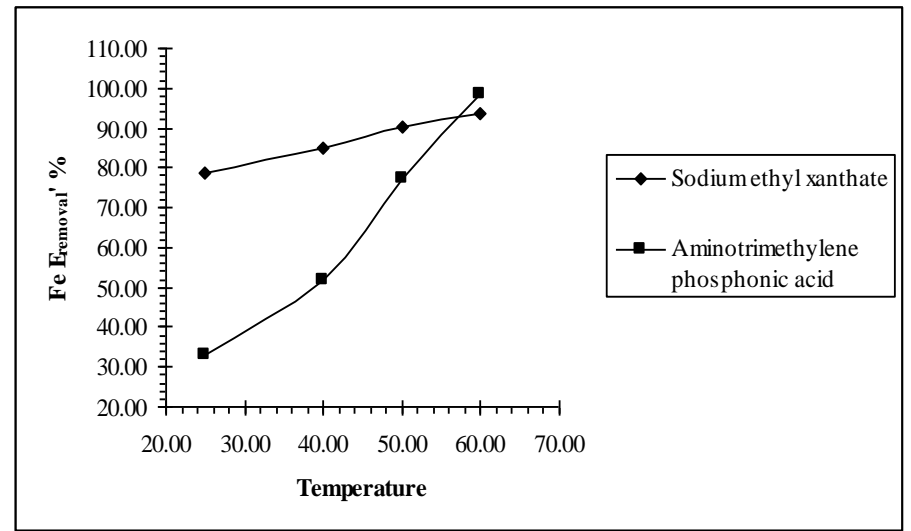

Fig.12. Effect of temperature on iron removal efficiency.

Highly pure grade phosphoric acid

Phosphoric acids are graded according to their physical properties and the concentration of some metallic and non-metallic impurities contained. Four grades are reported in literature. These grades are arranged according to their quality as: technical grade acid TGA < food grade acid FGA < pharmaceutical grade acid PGA < analytical grade acid AGA. Table 1 lists the physical 
properties and impurities content of these four grades. In the present work, highly pure grade phosphoric acid was successfully obtained from commercial Egyptian wet process phosphoric acid by solvent extraction technique using heptanol by three steps: a) extraction of $\mathrm{P}_{2} \mathrm{O}_{5}$ using heptanol, b) direct stripping of $\mathrm{P}_{2} \mathrm{O}_{5}$ using distelled water, the obtained stripped phosphoric acid by this method contains high concentration of iron $(4650 \mathrm{ppm})$ so that decreasing of the contained iron is necessary using one of the suggested methods of extraction of the iron using $\mathrm{D}_{2} \mathrm{EHPA}$ or removal of the iron using sodium ethyl xanthate. The purified stripped phosphoric acid is then evaporated to the proposed concentration.

Table 1 reveals that the difference in the physical properties is negligible. However, the difference in the impurities content expressed in ppm is pronounced. This was found true when the impurities determined in this investigation for crude acid, stripped phosphoric acid and finally produced acid are considered (Table 2).

TABLE 1. Physical properties and impurities content of the different grades of phosphoric acid.

\begin{tabular}{|c|c|c|c|c|}
\hline \multirow{3}{*}{ Constituent } & \multicolumn{4}{|c|}{ Phosphoric acid grades } \\
\hline & \multicolumn{4}{|c|}{ Concentration } \\
\hline & TGA & FGA & PGA & AGA \\
\hline $\mathrm{H}_{3} \mathrm{PO}_{4} \% \mathrm{w} / \mathrm{w}$ & $85.0 \%$ & $85.0 \%$ & $85.0 \%$ & $86.0 \%$ \\
\hline $\mathrm{P}_{2} \mathrm{O}_{5} \% \mathrm{w} / \mathrm{w}$ & $61.6 \%$ & 61.6 & $61.6 \%$ & 62.0 \\
\hline Density at $25^{\circ} \mathrm{C}$ & 1.6 & 1.6 & 1.6 & 1.7 \\
\hline \multicolumn{5}{|c|}{ Concentration ppm } \\
\hline $\mathrm{Fe}$ & 20.0 & 20.0 & 20.0 & 15.0 \\
\hline $\mathrm{F}^{-}$ & 100.0 & 10.0 & 10.0 & 10.0 \\
\hline $\mathrm{NO}_{3}^{-}$ & 20.0 & 5.0 & 5.0 & 5.0 \\
\hline $\mathrm{SO}_{4}^{-}$ & 200.0 & 100.0 & 50.0 & 20.0 \\
\hline $\mathrm{Cu}$ & 20.0 & 10.0 & 5.0 & 5.0 \\
\hline $\mathrm{Pb}$ & 10.0 & 5.00 & 1.0 & 3.0 \\
\hline
\end{tabular}

TABLE 2. Chemical composition of different types of phosphoric acid.

\begin{tabular}{|c|c|c|c|c|c|}
\hline Constituent & $\begin{array}{c}\text { Crude } \\
\text { WPA }\end{array}$ & $\begin{array}{c}\text { Stripped acid } \\
\text { using heptanol }\end{array}$ & $\begin{array}{c}\text { Stripped acid } \\
\text { using nonanol }\end{array}$ & $\begin{array}{c}\text { Purifn. using } \\
\text { sodium ethyl } \\
\text { xanthate }\end{array}$ & $\begin{array}{c}\text { Purifn. } \\
\text { using } \\
\text { ATMPA }\end{array}$ \\
\hline $\mathrm{P}_{2} \mathrm{O}_{5}, \%$ & 44.0 & 15.0 & 15.0 & 44.0 & 44.0 \\
\hline $\mathrm{Fe}, \mathrm{ppm}$ & 40560.0 & 4650.0 & 3200.0 & 1985.9 & 190.9 \\
\hline
\end{tabular}

Egypt. J. Chem. 56, No. 3 (2013) 
The data listed in Table 2 indicate that the finally produced acid is by far more superior compared with any of the grades reported in literature. Although the finally produced acids obtained in this investigation are more or less of the same grade, the acid obtained by extraction with nonanol contains the least impurities. Table 2 reveals also that the efficiencies of the alcohols used could be arranged as: $n$-nonanol $>n$-heptanol reefing thus to the function of the chain length. From the obtained results, $\mathrm{E}_{\mathrm{extn}}{ }^{\prime} \%$ decreased with the increase of the chain length of the solvent. This behavior may be explained as follows: the polarity of the alcohols decreases by increasing their chain length so, the alcohols become more immiscible with the phosphoric acid and the tendency to extract both $\mathrm{P}_{2} \mathrm{O}_{5}$ and undesirable impurities decreases. Perhaps other parameters such as the viscosity of the solvent, its stability and surface activity may contribute to the extraction efficiency. While in the stripping process the behavior may be explained as follows: the polarity of the alcohols decreases by the increase of the chain length, the $\mathrm{P}_{2} \mathrm{O}_{5}$ tendency to stay in the organic phase may decrease and hence the re-extraction of the $\mathrm{P}_{2} \mathrm{O}_{5}$ from loaded alcohol increases by increasing the alcohol chain length. All the previous interpretations may be the cause of that presence of the impurities in the purified phosphoric acid produced using long chain length alcohol are less than those present in the purified phosphoric acid using short chain length alcohol due to that the most immiscible alcohol with the phosphoric acid tend to extract less impurities. The iron concentration in the purified phosphoric acid using butanol was $525 \mathrm{ppm}$, in the case of using hexanol it reached $80 \mathrm{ppm}^{(10)}$ while the purification using nonanol gave phosphoric acid containing $5.00 \mathrm{ppm}$ iron only. El-Nadi ${ }^{(1)}$ studied the influence of alcohols on the extraction process in the acidic medium, his results revealed that increasing the chain length of the alcohols decreases the values of $\Delta \mathrm{G}$ and $\Delta \mathrm{S}$ which indicates that the system gets more spontaneous and more ordered in the direction: butanol > hexanol > heptanol > octanol > nonanol. Such behavior can suggest that water plays a role in the extraction system. In this concern, the dielectric constant values decrease for the different alcohols investigated with subsequent decrease in possible extraction of water with the extracted species.

\section{Conclusion}

Purification of WPA was carried out by solvent extraction using n-heptanol and n-nonanol. $\mathrm{P}_{2} \mathrm{O}_{5}$ was extracted from $9.2 \mathrm{M} \mathrm{H}_{3} \mathrm{PO}_{4}$ in two stages at $25{ }^{\circ} \mathrm{C}$ with aqueous / organic phase ratio equal 1:4 and 1:6 for heptanol and nonanol, respectively, while the shaking time was $10 \mathrm{~min}$. The percentages of extraction were 88.9 and $87.6 \%$ for heptanol and nonanol, respectively. Stripping of the acid from the organic phase with distilled water at room temperature was made from a system of aqueous / organic phase ratio $=2$. The stripping efficiencies of the alcohols follow the order: nonanol $>$ heptanol. The purification of stripped phosphoric acid to decrease iron content gave satisfactory results, the iron removal efficiency reached 95.1 and $99.5 \%$ by using sodium ethyl xanthate and aminotri methylene phosphonic acid, respectively. 


\section{References}

1. Amin, M. I. , Ali, M. M., Kamal, H. M., Youssef, A. M. and Akl, M. A., Recovery of high grade phosphoric acid from wet process acid by solvent extraction with aliphatic alcohols. Hydrometallurgy, 105, 115 (2010).

2. Hanna, A. A., Sibak, A. H. and Ali, A. F., Reduction of fluorine content in crude wetprocess phosphoric acid. Journal of Engineering and Applied Science, 45, 633-642 (1998).

3. Hanna, A. A., Youssef, N. S. and Ali, A. F., Purification of wet process phosphoric acid by solvent extraction. Egypt Journal Chemistry, 38311 (1995).

4. Moussa, A. I., Extraction of phosphoric acid from various aqueous solutions using tributyl phosphate. Chemical Engineering, 51, 39 (2007).

5. Hannachi, A., Habaili, D., Chtara, C. and Ratel, A., Purification of wet process phosphoric acid by solvent extraction with TBP and MIBK mixtures. Separation and Purification Technology, 55, 212 (2007).

6. Abu-Raia, A., Purification of commercial phosphoric acid using organic solvents, M.Sc Thesis, Faculty of Science, Tanta University, 112 (2006).

7. El-Asmy, A. A., Serag, H. M., Mahdy, M. A. and Amin, M. I., Purification of phosphoric acid by minimizing iron, copper, cadmium and fluoride. Separation and Purification Technology, 61, 287-292 (2008).

8. El-Shall, H. and Abdel-Aal, E.A., Decreasing iron content in wet process phosphoric acid, Final Report, Department of Materials Science and Technology, Florida University, Feb. 2-15 (2001).

9. Haraldsen, H.F.T., United State Patent, " Method for removal of heavy metals from phosphoric acid containing solutions ", No. 4, 986,970, Jan. 22, (1991).

10. Amin, M. I., Removal of metallic and non metallic impurities frpm wet process phosphoric acid using different separation techniques, $P h D$, Chemistry Department, Mansoura Universitry (2010).

11. El-Nadi, Y. A., Influence of alcohols on the extraction of cerium (iv) by aliquat-336 in kerosene. Int. J. Miner. Process, 82, 14-22 (2007).

(Received 27/8/2013;

accepted 25/11/2013) 


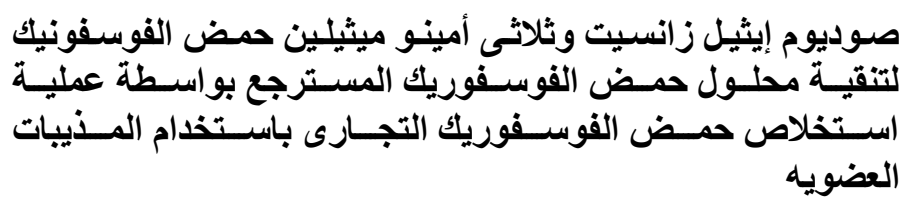

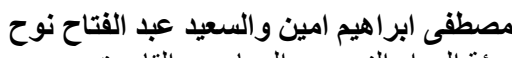
هيئة المو اد النوريه ـ المعادى ـ القاهرة ـ مصر.

تنقية حمض الفوسفوريك تتم عن طريق الاستخلاص باستخدام المذيبات العضويه

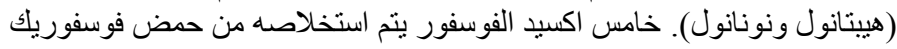

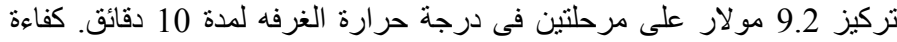

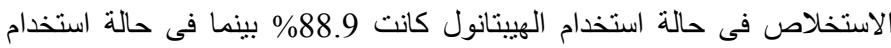

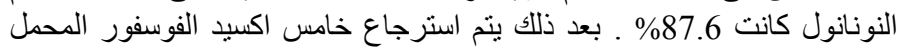

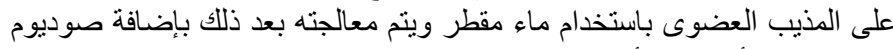

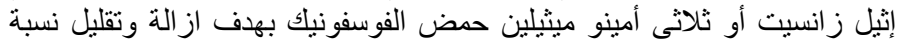

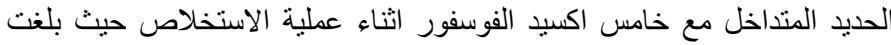

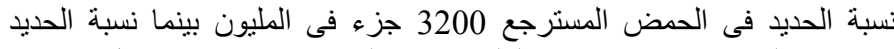

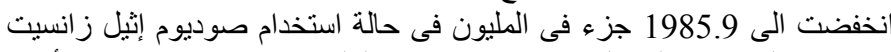
بينما هذه النسبة وصلت الى 190.9 جزء 1985.

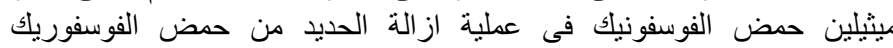
المسترجع من عملية استخلاص خامس اكسيد الفوسفور من حمض الفئ الفوسفوريك الفئ التجارى باستخدام المذيبات العضويه. 